\title{
What are the most effective interventions to improve physical performance in pre-frail and frail adults? A systematic review of randomised control trials
}

Tara Kidd ${ }^{1}$, Freda Mold², Claire Jones², Emma Ream², Wendy Grosvenor², Märtha Sund-Levander ${ }^{3}$, Pia Tingström ${ }^{3}$ and Nicola Carey $^{2^{*}}$ (D)

\begin{abstract}
Background: With life expectancy continuing to rise in the United Kingdom there is an increasing public health focus on the maintenance of physical independence among all older adults. Identifying interventions that improve physical outcomes in pre-frail and frail older adults is imperative.

Methods: A systematic review of the literature 2000 to 2017 following PRISMA guidelines and registered with PROSPERO (no. CRD42016045325).

Results: Ten RCT trials fulfilled selection criteria and quality appraisal. The study quality was moderate to good. Interventions included physical activity; nutrition, physical activity combined with nutrition. Interventions that incorporated one or more physical activity components significantly improved physical outcomes in pre-frail and/or frail older adults.

Conclusions: Physical activity interventions are key to maintaining independence in pre-frail and frail older adults. A lack of consensus regarding the definition of frailty, and an absence of core measures to assess this means any attempt to create an optimal intervention will be impeded. This absence may ultimately impact on the ability of older and frail adults to live well and for longer in the community.
\end{abstract}

Keywords: Frailty, Successful aging, Physical activity, Nutrition, Intervention

\section{Background}

Frailty, a geriatric syndrome characterized by unintentional weight loss, low muscle strength, feeling of exhaustion, reduced physical activity capacity and slow walking speed [22, 34, 46], affects $4-60 \%$ adults aged $\geq 65$ years [11] and is associated with significantly increased risk of poor physical health, hospitalization, nursing home care and mortality $[18,29,41]$. In an aging society the rapidly increasing number of frail older adults and associated rise in healthcare expenditure [19] is seen as a major challenge facing health and social care [1].

* Correspondence: n.carey@surrey.ac.uk

${ }^{2}$ School of Health Science, University of Surrey, Surrey GU2 7YH, UK

Full list of author information is available at the end of the article
Despite growing interest in this topic a widely accepted definition and clear criteria for frailty is lacking [7]. Currently, the Cardiovascular Health Study (CHS) frailty phenotype, also known as the Fried Criteria [22], which focuses on physical phenotype, is the most widely used tool for assessing frailty status [21].

There is a growing consensus that interventions targeting the physical phenotype associated with increased risk for adverse outcomes in older adults; particularly mobility, strength, balance, nutrition and physical activity, may offer the best opportunity to prevent, delay, or reverse existing symptoms of physical frailty [3, 9]. Evidence from two recent systematic reviews identified a range of interventions, i.e. physical activity, nutrition, geriatric assessment or a blend of these delivered in primary care, community settings or at home, and found 
those that incorporated a physical activity component were consistently the most effective at improving frailty status, physical outcomes (e.g. body mass index, muscle mass, strength, gait speed, exhaustion, physical activity) and/or functional ability [14, 39]. However, caution must be applied when interpreting change in frailty or functional ability as a primary outcome measure, as there is still a lack of agreement regarding clinically meaningful reduction in frailty or functional ability [2, 37, 38]. In contrast, performance based physical outcome measures such as mobility, balance, body mass and activity levels, have consistently reported strong associations with future health, functional ability, and service use in older and frail adults $[25,27,47]$.

Identifying effective interventions, with the potential to promote successful aging and, minimise the burden of care on health care services is therefore crucial [3]. Building on previous work, by focusing only on randomised controlled trail (RCT) interventions that specifically measure one or more physical performance outcomes, a systematic review was undertaken to explore potential preventative applications of these interventions in pre frail and frail older adults.

\section{Research question}

"What are the most effective interventions for improving physical performance outcomes in pre-frail and frail older adults?"

\section{Methods}

A systematic review, registered with PROSPERO (no. CRD42016045325), using evidence from 2010-March 2017 and following Preferred Reporting Items for Systematic Reviews and Meta-Analyses (PRISMA) guidelines [13] was undertaken.

\section{Definition of terms}

1. Physical performance was defined as an observable physical outcome measure related to the frailty criteria [22] specified for this study, including gait speed, grip strength, physical activity levels, mobility, balance, muscle mass, and body mass index. Body Mass Index was used as an indicator of weight loss or gain [15].

\section{Search strategy}

Targeted searches of Cochrane Database of Systematic Reviews, MEDLINE, EMBASE, CINAHL and PsycINFO were conducted using index/MeSH (Medical Subject Heading) and string of keyword terms, (Frail Elderly) + (early intervention) + (health care, health service, patient care). See Additional file 1 for search terms, and example search string.

\section{Eligibility criteria}

Articles were included that comprised of:

2. RCTs reporting one or more observable measure of physical performance related to frailty criteria (e.g. gait speed, grip strength, physical activity levels, mobility, balance, muscle mass, body mass index) as this study design generally supports greater validity and causal inference [40].

3. Pre-frail or frail adult participants, aged $>65$ years.

4. Peer reviewed publications, available in English.

Studies were excluded if physical performance was only measured using Activities in Daily Living (ADL) or Instrumental Activities of Daily Living (IADL) to ensure physical frailty, rather than disability was assessed. Participants were also excluded if they had dementia, psychosis/personality disorders, or were institutionally confined.

\section{Study selection and screening}

Results were exported into EndNote X7 software (Thomas Corporation) and duplicates removed before titles and abstracts were screened in relation to the inclusion/exclusion criteria. Citations were screened by all members of the research team (NC, FM, ER, WG, MSL, PT) and checked independently by the two other reviewers (TK \& CJ). All reviewers confirmed the eligibility of the identified studies. Disagreement was resolved during discussions in the author team meeting. Excluded papers including systematic reviews were scanned to identify any additional articles.

\section{Data extraction}

Data extraction was conducted by three researchers (TK, CJ, EM) using a pre-designed data extraction form to capture details about study, data collection methods, sample, outcome measures, intervention content, duration of follow-up, analysis methods, results, intervention effectiveness and limitations. The template for intervention description and replication [TIDieR] [31], designed to improving intervention reporting, was used to record intervention content.

\section{Strength of evidence assessment of studies}

The Cochrane Risk of Bias Tool [30] comprising seven domains: sequence generation, allocation concealment, blinding of participants and personnel, blinding of outcomes assessed, treatment of incomplete data, selective outcome reporting and other risks of bias, was used to analyse each study. The risk of bias in each subcategory 
was classified as high, low or unclear. Assessment of bias was conducted independently by 2 authors (TK \& CJ), decisions compared and discussed to achieve consensus (Additional file 2).

\section{Results}

Searches across all database and additional searches yielded $n=2511$ results. After applying the inclusion/ exclusion criteria $n=33$ remained. Full text articles were retrieved and on closer inspection $n=23$ did not fulfil the review eligibility. A total of 10 articles were eligible and included in the analysis (see Fig. 1 and Table 1).

\section{Study characteristics}

Of the 10 included studies 4 were physical activity interventions [24, 48, 49, 51], 5 physical activity plus nutrition $[6,8,20,35,52]$, and 1 nutrition only interventions [50]. Methodological quality ranged from adequate $(n=3)$ to excellent $(n=7)$ (see Additional file 2).

Multiple outcomes were assessed both within and across studies, with mobility or its components the most commonly reported outcome $[6,8,20,24,35,48,49,52]$, followed by physical capacity $[24,35,50,52]$, service use and mortality [8], and falls [20,51].

Six studies were based in a primary care setting including participants home $[6,8,20,24,35,52], 3$ in secondary (hospital) care $[48,49,51]$, with one unclassified setting [50].

Studies were predominantly delivered face-to-face on an individual basis $[6,8,20,24,48,49]$, with 1 utilising group delivery [51], and 2 remote delivery methods [50, 52]. Follow-up ranged from 1 week-24 months, with most reporting data at 3,6 or 12 months. Sample sizes ranged from 41 to 397 , and studies were conducted in a wide variety of countries, the most commonly reported was Australia $(n=2)$, followed by France, Norway, Sweden, the Netherlands, Canada, Singapore, Japan, and Barcelona (all $n=1$ ). No studies originated from the UK.

All 10 articles included a measure of physical frailty. Frailty was not clearly defined, which was reflected in the heterogeneity of assessment measures. Validated measures used included the CHS frailty phenotype or

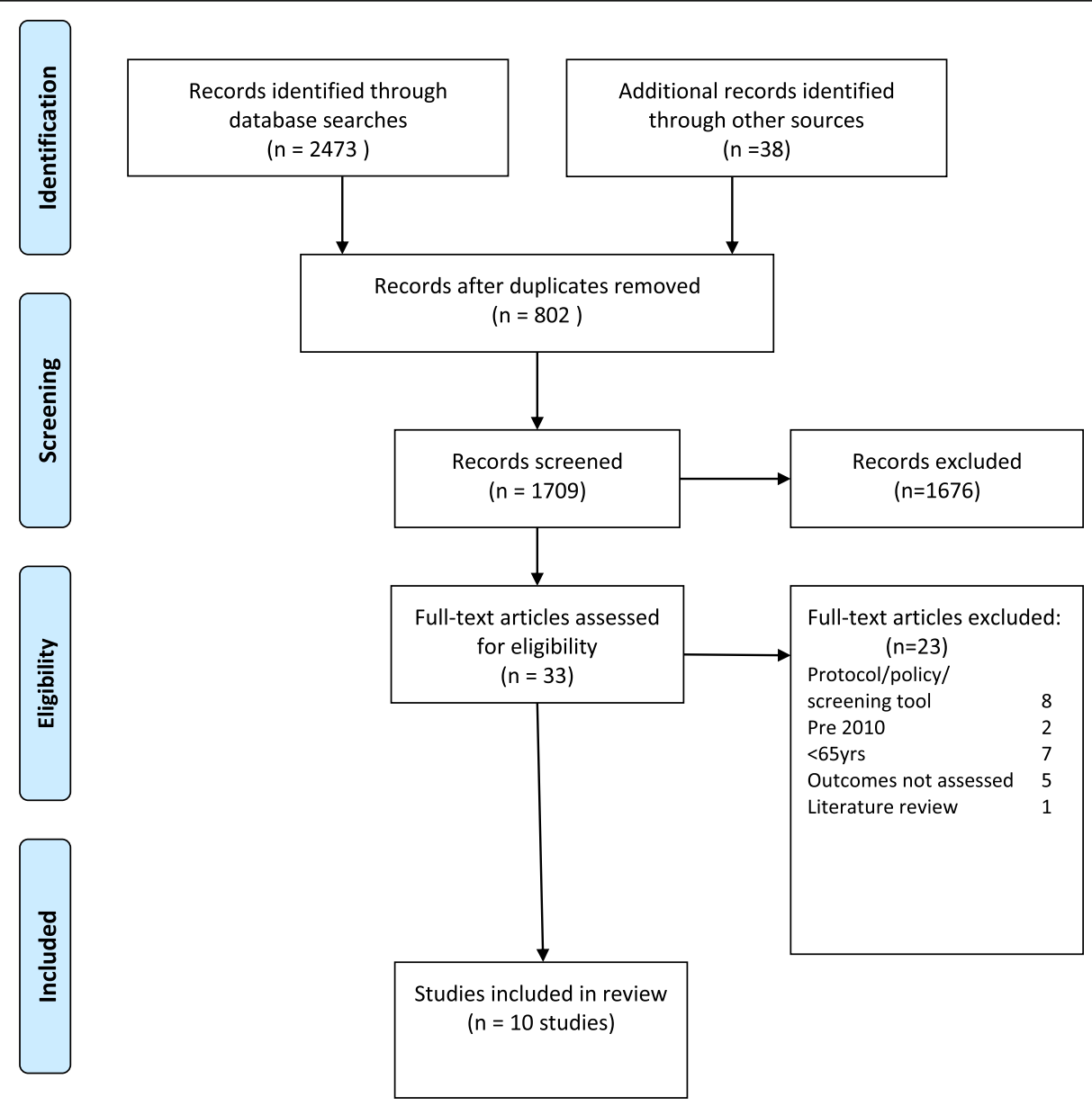

Fig. 1 Flow diagram detailing the search process 


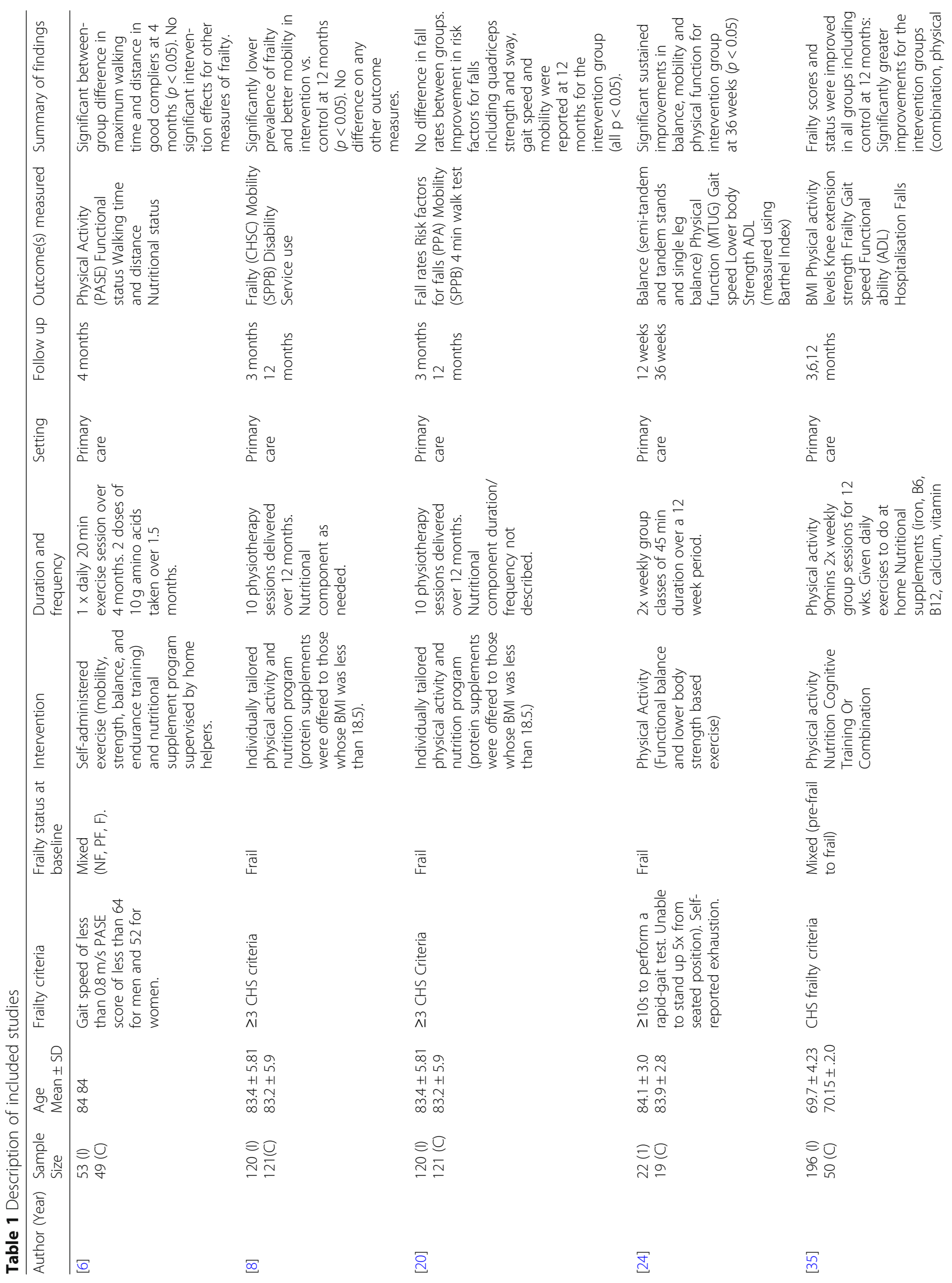




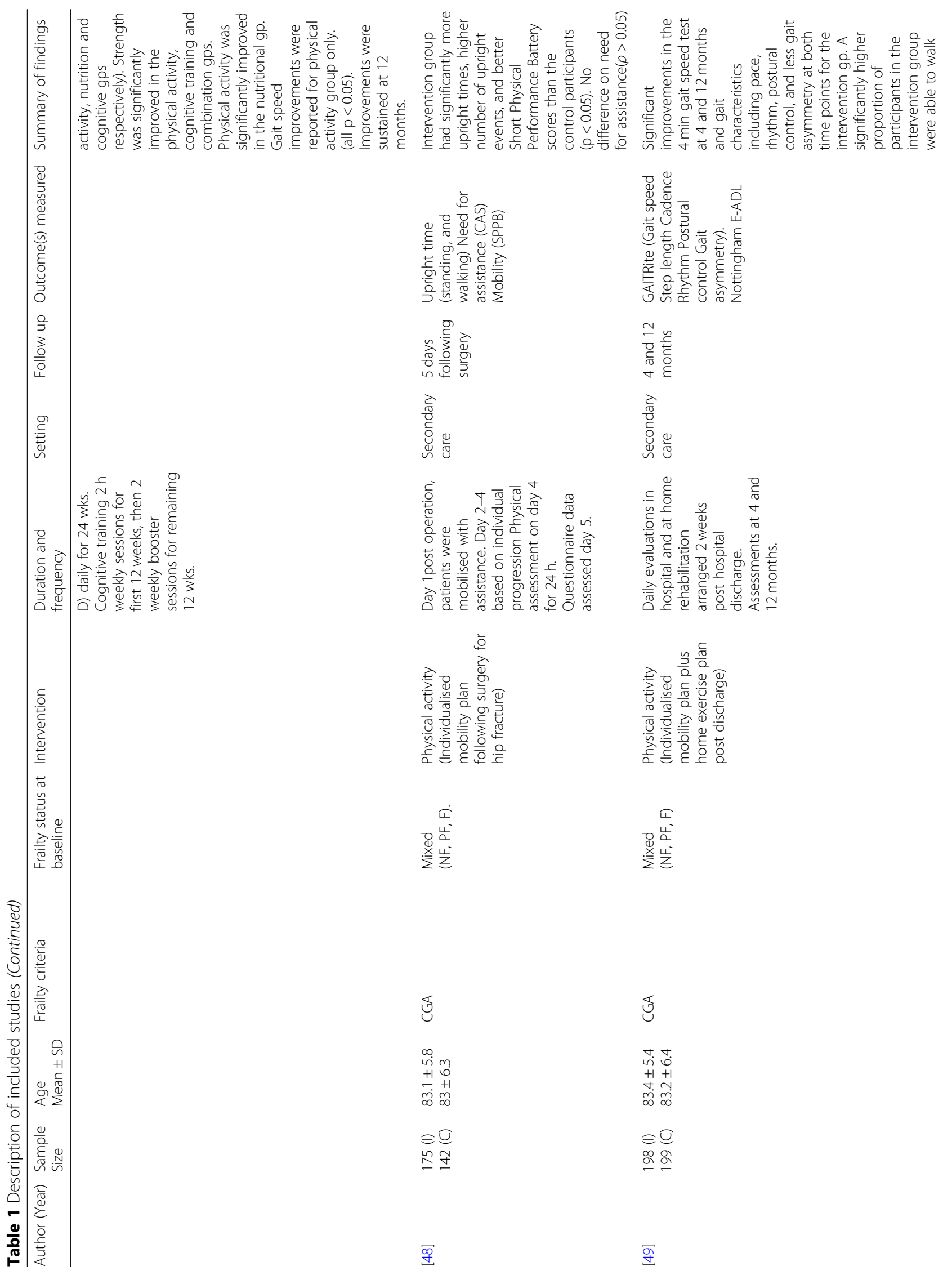




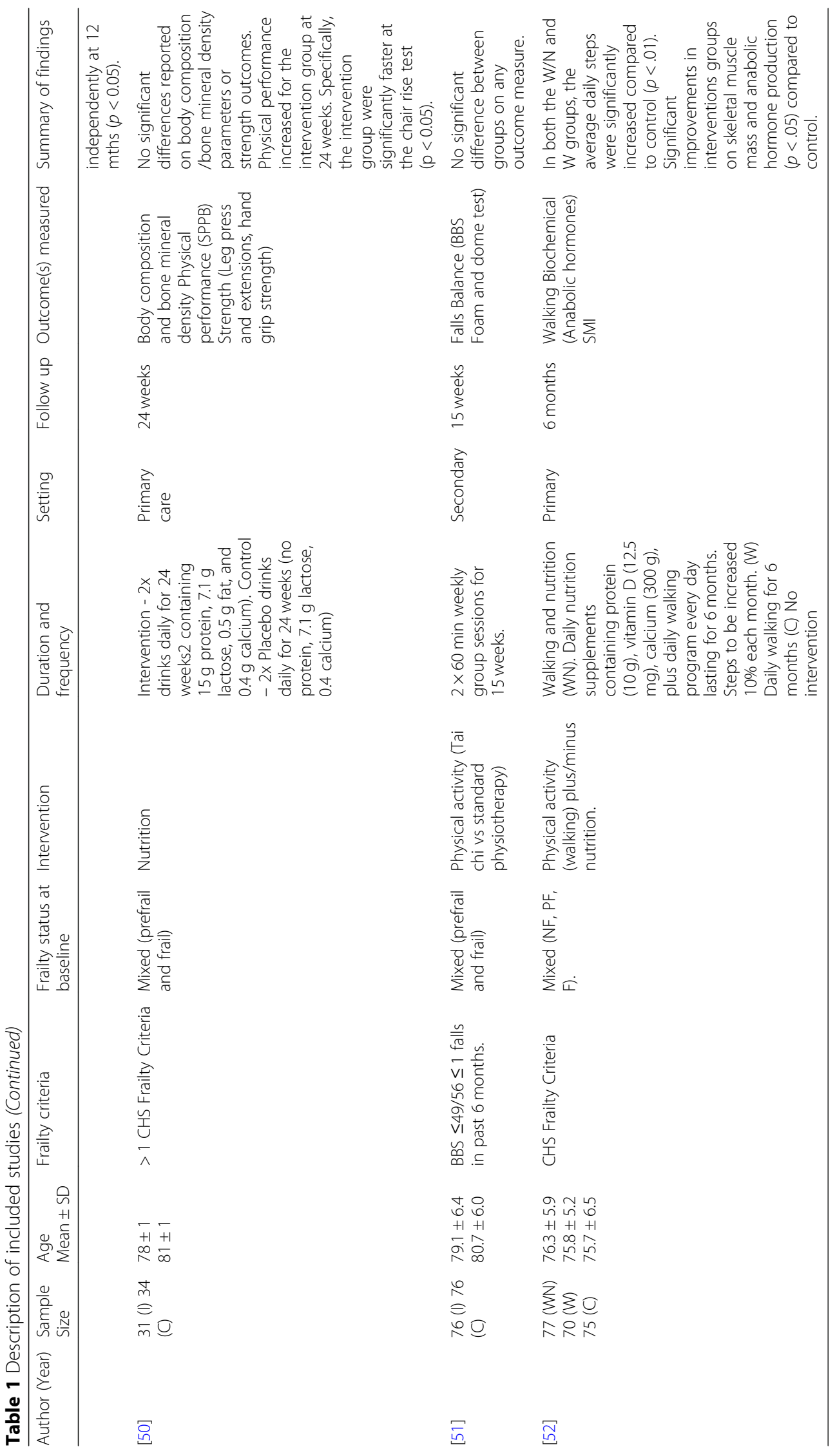


Fried criteria [22], Comprehensive Geriatric Assessment, and Physical Activity Scale for Elders.

\section{Physical activity interventions Primary care setting}

Giné-Garriga et al. [24] incorporated group based exercise focusing on balance, and upper and lower body strength, along with function focused activities designed to mimic everyday tasks. The intervention comprised of twice weekly $45 \mathrm{~min}$ classes over 12 weeks. Significant improvements were reported in the primary outcome measures of the Barthel Index, rapid gait test, and stand up test, which were maintained at 36 weeks (all $p<0.05$ ) [24]. Significant improvements were also reported for the intervention group in secondary outcomes including balance, gait speed, and lower body strength $(p<0.05)$.

\section{Secondary care settings}

A total of 3 physical activity intervention studies were based in hospital settings. One focused on falls prevention [51], while 2 examined effects of a physical function intervention on mobility outcomes following a surgical procedure $[48,49]$. The falls prevention program intervention compared Tai Chi with conventional physical therapy for frail older adults at risk of falls [51]. Both groups received twice weekly $60 \mathrm{~min}$ sessions for 15 weeks via a group setting for Tai Chi, and individually for the conventional treatment. Both groups improved but the Tai Chi group did not reduce fall frequency significantly better than conventional treatment, even though a trend emerged for lower fall rates in the Tai Chi group. Given that both the Tai Chi and conventional treatment groups had over $40 \%$ drop out rates across the duration of the intervention ( $n=29$ and 35 respectively), any effects may be underestimated due to a lack of statistical power.

Two studies reported on the Trondheim hip fracture RCT $[48,49]$ which examined physical activity and mobility in the immediate post-surgery days on a geriatric ward compared with a conventional post-surgery ward [48]; assessing gait characteristics at 4 and 12 months post intervention ([49]). The post-operative mobilisation plan comprised: mobilisation $24 \mathrm{~h}$ following surgery; mobilisation goals based on initial performance, training and practising activities related to daily living; strength training was also included if required, and ward routines designed to prohibit long periods of sitting or lying.

Taraldsen et al. [48] found that those receiving the intervention had significantly greater upright time ( $p=$ $0.016)$, number of upright events $(p=0.005)$, and better physical performance than conventionally treated counterparts four days following surgery $(p=0.002)$ [49] found that significantly more patients could perform the 4 min gait speed test at $4(p=0.049)$, and 12 months $(p=0.005)$ than conventionally treated patients, and overall had better gait characteristics including pace $(p=$ $0.001)$, rhythm $(p=0.019)$, postural control $(p=0.027)$, and less gait asymmetry $(p=0.004)$ at 12 months. A significantly higher proportion of participants in the intervention group were able to walk independently $(p=$ $0.006)$, had better outdoor mobility $(p=0.015)$, and greater independence when using public transportation at 12 months compared to controls $(p=0.040)$. Length of stay was slightly longer for the intervention group (12.6 vs 11 days); however, the intervention was found to have an $88 \%$ probability of being both less costly and more effective than orthopaedic care in the long run.

\section{Physical activity plus nutrition \\ Primary care settings}

Of the 5 studies examining physical activity plus nutrition in a primary care setting, Fairhall et al. [20] and Cameron et al. [8] report data taken from the same RCT of a multifactorial intervention designed to target frailty characteristics including nutritional assessment, physiotherapy and medical management to reduce fall rates. Ten physiotherapy sessions, delivered over a 12 month period, focussed on strength and balance, with high energy, high protein supplements offered to those whose BMI was less than 18.5 ( $n=60,50 \%$ of sample).

In total, 25 participants (21\%) were recommended vitamin D supplements. Adherence to the nutritional intervention ranged between 26 to 50\%. Fairhall et al. [20] found no difference in fall rates between the intervention and conventional treatment groups $(p>0.05)$. Cameron et al. [8] found significant reductions in frailty status at 12 but not 3 month follow up $(p=0.02)$. Improvement in physical performance including strength and gait speed were reported at 12 months (all $p<0.001$ ). No differences were found on mortality, hospital admissions, permanent admissions to nursing care facilities, or quality of life outcomes $(p>0.05)$.

Bonnefoy et al. [6] devised an intervention around existing home help services which combined a selfadministered exercise program, (participants were prescribed exercises by a physiotherapist, received a booklet explaining how to perform exercises, a poster showing pictures of the exercises, and how to fill in a compliance diary) alongside a $10 \mathrm{~g}$ amino-acid supplementation to be taken under the supervision of the home help. It was expected that the visitation of the home help would also prevent sedentariness as they were trained to encourage physical activity. Overall adherence was poor to the exercise and nutritional components, with only $44 \%$ ( $n=23 / 53)$ of participants being fully compliant. The results of the study suggest limited impact of exercise and nutrition on markers of frailty, including body composition indicators, mobility, or activities in daily living. 
$\mathrm{Ng}$ et al. [35] randomised participants with a mean age of 70 years to physical exercise, nutrition, cognitive training or combination treatment program for 6 months to examine the impact on frailty characteristics, with specific focus on mobility and strength performance outcomes. Frailty was assessed and included participants who were classified as pre-frail or frail, though no stratified analyses were conducted. The exercise group $(n=48)$ received a program tailored to their specific ability in classes for 90mins twice weekly for 12 weeks which focused on strength and balance. This was followed by a 12 weeks of home exercises. The nutritional group $(n=49)$ received supplements of iron and folate, vitamins B6 and B12, calcium and vitamin D for 24 weeks. Cognitive training $(n=50)$ involved $2 \mathrm{~h}$ weekly sessions for 12 weeks of cognitiveenhancing activities designed to stimulate short-term memory, and enhance attention, informationprocessing skills, reasoning and problem solving abilities. The following 12 weeks included fortnightly booster sessions. The combination group $(\mathrm{n}=49)$ experienced all treatments. Frailty scores were significantly reduced at 6 and 12 months in all groups (all $p<0.05$ ), with combination group reporting the greatest reduction (mean change $=5.00$ ), followed by physical therapy (mean change $=4.05)$, nutrition (mean change $=2.98)$ and cognitive therapy (mean change $=2.89$ ). However, there was no clear statistical difference between treatment groups on improving physical performance. Lower body strength improved in the combination, physical activity, and cognition groups $(p=0.009)$; gait speed improved in the physical activity group only $(p<0.001)$; overall physical activity improved in the nutrition group ( $p=0.038$ ).

The final study by Yamada et al. [52] was the only study that delivered the intervention by remote delivery methods. This was a pedometer based walking program and nutritional supplement (protein and vitamin D) delivered over a 6 month period. Participants were randomly assigned to a walking group $(n=71)$, walking plus nutrition $(n=79)$, or control group $(n=77)$. Adherence levels were very high, with $80 \%$ adherence reported for the nutritional component, and $100 \%$ for the walking initiative. Muscle mass and biochemical outcomes were assessed. Both the walking and walking plus nutrition groups were successful in improving biochemical outcomes associated with improved muscle mass (IGF-1, $25(\mathrm{OH}) \mathrm{D})$ and skeletal muscle mass index compared with the control group $(p<0.05)$, but only the walking plus nutrition group had significantly greater improvements in Dehydroepiandrosterone-Sulfate (DHEA-S) $(\mathrm{p}<0.05)$. The number of daily steps also increased significantly in both groups, with an increase from 4471 to 6067 steps in the walking plus nutrition group, and an increase from 3795 to 5394 steps in the walking group. Sub-group analysis was conducted separately for non-frail and frail participants; however the sample size for this analysis was small with only 31 frail vs 46 nonfrail in the walking plus nutrition group, 15 frail vs 55 non-frail in the nutrition only group, 25 frail vs 50 nonfrail in the control group; however, cautious interpretation suggests that both frail and non-frail participants benefited in improved physical performance from the intervention in comparison to the control group.

\section{Nutrition}

\section{Primary care setting}

Tieland et al. [50] recruited pre-frail and frail participants to receive twice daily protein supplements vs a placebo over a 24 week period; however despite high reports of adherence, there was no difference in any biochemical measure, skeletal muscle mass, or in hand or lower body muscle strength compared to the placebo group. Only physical performance, (a composite score of gait, balance and chair rise test) significantly improved in the protein group at 24 weeks $(p=0.02)$. The authors report that the increase in physical performance was of substantial clinical relevance and translates to a 30\% relative risk reduction for disability and a reduced risk for institutionalization and mortality.

\section{Discussion}

This review found interventions including one or more physical activity components were successful at improving physical performance in pre-frail and frail older adults, with some evidence to suggest deterioration was ameliorated up to 12 months post-intervention [48, 49]. Contrary to previous work, we found no clear evidence to support the superiority of multi-domain interventions over simple interventions [14]. Given the increasing concerns regarding the projected rise in older people in relation to future service provision this review is timely, and of significant importance.

Several factors related to intervention success: firstly, interventions targeted to improve physical condition, e.g. resistance training to build muscle mass and strength, and a clearly defined outcome (e.g. upper or lower body strength) reported significant improvements [24, 48]. Secondly, interventions combining resistance and balance training were most successful in treating physical symptoms associated with frailty, reducing falls, and maintaining health benefits $[20,25,35,48,49]$. Combining different types of physical exercise may therefore support maximum impact on all physical performance components associated with frailty i.e. mobility, balance, body mass, levels of activity.

Thirdly, supervised interventions across primary and secondary care reported improved physical performance $[8,20,24,35,48-50]$. Supervision of physical exercise 
may be an essential element for success for a number of reasons: importantly, supervision promotes exercise regimen adherence, which is critical to experiencing beneficial effects. Relatedly, frail individuals are likely to have concerns about their ability and falling which supervision and support can help overcome [4, 28]. A significant proportion of frail older adults are cognitively impaired, which may also affect exercise regimen adherence. While this review did not examine interventions in people with cognitive decline, studies report promising results for supervised physical activity interventions in people with dementia [26], suggesting that benefits of supervised physical activity can be applied across the frailty spectrum.

One community-led supervised physical activity interventions also demonstrated successful results [24]. Community-based exercise, such as Tai Chi, has previously been shown to reduce hospital admissions, falls, and admission to long-term healthcare [5, 23]. This is particularly relevant in the UK where government policy priority emphasises the need to move the provision of non-emergency healthcare from acute to primary care [16].

Our results tentatively suggest the potential for home based individualised physical training programs for older adults [52]. Evidence suggests that interventions could be delivered remotely via the telephone [36], mobile applications [44] or virtual reality and gaming technology [45]. Initial results appear promising with reported gait and balance improvements, but these approaches are yet to be tested in frail older adults [45]. Home-based programs are more accessible, and potentially cost effective, eliminating transportation barriers for many frail adults, enabling them to be active, live well and for longer in their local community $[16,43]$.

Given that reducing falls, service use and/ or admission to a permanent care facility is a core component of current health care policy $[16,19]$ the results from this review are encouraging. Targeted interventions to improve balance and muscle strength have been shown to reduce falls risk, and subsequent hospital admissions [32, 42]. Although few of the reviewed studies reported on falls, service use or placements [48, 49], the limited evidence indicated that targeted physical interventions were associated with improvements in these outcomes.

While the benefits of nutritional intervention cannot be determined by one study, the wider literature suggest the potential benefits of targeting those who are malnourished [10]. Malnutrition is associated with poor health outcomes including reduced functional status, decreased muscle mass, higher risk of permanent care placement and mortality [12,33]. This provides some support for international guidelines suggesting that nutritional interventions should be given as a preventative measure to older people at risk of malnutrition [17], for example, frail pre-surgical patients to enhance recovery. Hospital based pre-assessment clinics would be ideal setting to incorporate mandatory screening for malnutrition and delivering this targeted type of intervention.

\section{Limitations}

Reviewed interventions were designed to achieve rapid improvements in physical performance over relatively short time periods; however, disparity between studies meant the intensity and frequency of intervention delivery needed to achieve and maintain these physical benefits was unclear. Also, information about participants' activity levels at follow-up was not reported and it is not clear if the reported physical benefits were due entirely to the intervention, or if there had been some sustained behaviour change in physical activity.

On reflection, the search strategy for this review may have been too broad. Varied definitions of frailty were incorporated across the studies making meaningful comparisons difficult. Information was often limited regarding the proportion of participants who fulfilled pre-frail, or frail physical criteria within studies. Small sample sizes meant that pre-frail and frail participants were often grouped together for analyses purposes, so it was not possible to ascertain whether changes in physical performance translated into outcomes that were clinically meaningful. Consequently, we were unable to consider preventative vs. targeted treatment effects in these groups. Correspondingly, there was a wide range of outcome measures used across studies which perhaps reflects the lack of clarity over what it means to be identified as frail.

\section{Conclusion}

This review has systematically explored the effectiveness of interventions to improve physical performance in prefrail and frail adults. The small number of RCT available to include suggests a significant gap in the research literature. Relatedly, given the UK government's commitment to improve health outcomes by 2020, it was surprising no eligible UK studies were found. Despite this, the results tentatively suggest that tailored, supervised, physical activity interventions are effective at improving physical performance components associated with frailty in both primary and secondary care settings. However, until there is an agreed definition for frailty and a core set of measures to assess this, any attempt to create an optimal validated intervention will be impeded. This absence may ultimately impact on the ability of older and frail adults to live well and for longer in the community. 


\section{Additional files}

Additional file 1: Example search string. (DOCX $22 \mathrm{~kb}$ )

Additional file 2: Risk of Bias. (DOCX $13 \mathrm{~kb}$ )

\section{Abbreviations}

Ab: Abstract word; ADL: Activities of Daily Living; BBS: Berg Balance Scale; BMI: Body Mass Index; CAS: Cumulated ambulation score:

CGA: Comprehensive geriatric assessment; CHSC: Cardiovascular Health Study Criteria; DHEA-S: Dehydroepiandrosterone-Sulfate; F: Frail; IADL: Instrumental Activities of Daily Living; LOS: Length of stay; MH: Main index/ MeSH term; MNA: Mini nutritional assessment; MTUG: The modified timed up and go test; NF: Non frail; PASE: Physical activity Scale for Elders; PF: Pre-frail; PI: Post intervention; PROSPERO: International prospective register of systematic reviews; PRSIMA: Preferred Reporting Items for Systematic Reviews and MetaAnalyses; PT: Publication Type; RCT: Randomised Controlled Trial; SMI: Skeletal muscle mass index; SPPB: Short physical performance battery; SU: Subject Heading; Ti: Title word; UK: United Kingdom

\section{Acknowledgements}

We would like to thank Evie Michailidis who helped with extracting the evidence.

\section{Authors' contributions}

Conception \& Design; NC, FM, TK: Data analysis: TK, FM, NC, CJ, ER, WG, MSL, PTL: Interpretation of data; TK, FM, NC, CJ, ER, WG, MSL, PTL. Draft and revising work TK, NC, FM; All authors approved the final version.

\section{Funding}

The paper is based a larger piece of work that was funded by the Kent, Surrey and Sussex Academic Health Science Network (KSS AHSN).

\section{Availability of data and materials}

Data sharing is not applicable to this article as no datasets were generated or analysed during the current study.

\section{Ethics approval and consent to participate}

Not applicable.

\section{Consent for publication}

Not applicable.

\section{Competing interests}

The authors declare that they do not have any competing interest.

\section{Author details}

${ }^{1}$ School of Natural Sciences and Psychology, Liverpool John Moores University, Liverpool, UK. 'School of Health Science, University of Surrey, Surrey GU2 7YH, UK. ${ }^{3}$ Department of Medical and Health Sciences, Linköping University, Linköping, Sweden.

Received: 19 December 2018 Accepted: 24 June 2019 Published online: 11 July 2019

\section{References}

1. Age UK. (2015). Later Life in the United Kingdom 2015. Retrieved from http://www.ageuk.org.uk/Documents/EN-GB/Factsheets/Later_Life_UK_ factsheet.pdf?dtrk=true.

2. Alley DE, Hicks GE, Shardell M, Hawkes W, Miller R, Craik RL, et al. Meaningful improvement in gait speed in hip fracture recovery. J Am Geriatr Soc. 2011;59(9):1650-7.

3. Anton SD, Woods AJ, Ashizawa T, Barb D, Buford TW, Carter CS, et al. Successful aging: advancing the science of physical independence in older adults. Ageing Res Rev. 2015;24:304-27.

4. Arantes PM, Dias JMD, Fonseca FF, Oliveira AM, Oliveira MC, Pereira LS, Dias RC. Effect of a program based on balance exercises on gait, functional mobility, fear of falling, and falls in Prefrail older women: a randomized clinical trial. Topics in Geriatric Rehabilitation. 2015;31(2):113-20.

5. Beswick AD, Rees K, Dieppe P, Ayis S, Gooberman-Hill R, Horwood J, Ebrahim S. Complex interventions to improve physical function and maintain independent living in elderly people: a systematic review and meta-analysis. Lancet. 2008;371(9614):725-35.

6. Bonnefoy M, Boutitie F, Mercier C, Gueyffier F, Carre C, Guetemme G, et al. Efficacy of a home-based intervention programme on the physical activity level and functional ability of older people using domestic services: a randomised study. J Nutr Health Aging. 2012;16(4):370-7 Retrieved from https://doi.org/10.1007/s12603-011-0352-6.

7. Bouillon K, Kivimaki M, Hamer M, Sabia S, Fransson El, Singh-Manoux A, et al. Measures of frailty in population-based studies: an overview. BMC Geriatr. 2013;13(1):64

8. Cameron ID, Fairhall N, Langron C, Lockwood K, Monaghan N, Aggar C, et al. A multifactorial interdisciplinary intervention reduces frailty in older people: randomized trial. BMC Med. 2013;11(1):1.

9. Cesari $M$. The multidimensionality of frailty: many faces of one single dice Jutr Health Aging. 2011;15(8):663-4.

10. Chevalier S, Saoud F, Gray-Donald K, Morais JA. The physical functional capacity of frail elderly persons undergoing ambulatory rehabilitation is related to their nutritional status. J Nutr Health Aging. 2008;12(10):721-6.

11. Collard RM, Boter H, Schoevers RA, Oude Voshaar RC. Prevalence of frailty in community-dwelling older persons: a systematic review. J Am Geriatr Soc. 2012;60(8):1487-92.

12. Covinsky KE. Malnutrition and bad outcomes. J Gen Intern Med. 2002;17(12):956-7.

13. David Moher D, Liberati A, Tetzlaff J. Preferred reporting items for systematic reviews and meta-analyses: the PRISMA statement. PLoS Med. 2009;6(7):e1000097.

14. Dedeyne L, Deschodt M, Verschueren S, Tournoy J, Gielen E. Effects of multi-domain interventions in (pre) frail elderly on frailty, functional, and cognitive status: a systematic review. Clinical interventions in aging. 2017; 12:873.

15. Deitel M, Greenstein RJ. Recommendations for reporting weight loss. Obes Surg. 2003;13(2):159-60.

16. DH. (2015). Moving healthcare closer to home. Available from:https://www. gov.uk/guidance/moving-healthcare-closer-to-home.

17. Elia M, Russell C, Stratton R. Malnutrition in the UK: policies to address the problem. Proc Nutr Soc. 2010;69(04):470-6.

18. Ernsth Bravell M, Westerlind B, Midlov P, Ostgren CJ, Borgquist L, Lannering C, Molstad S. How to assess frailty and the need for care? Report from the study of health and drugs in the elderly (SHADES) in community dwellings in Sweden. Arch Gerontol Geriatr. 2011;53(1):40-5. https://doi.org/10.1016/j. archger.2010.06.011.

19. European Commission. Multidimensional aspects of population ageing. In: Population ageing in Europe: facts, implications and policies: outcomes of EU-funded research. Luxumberg: Publications Office of the European Union; 2014

20. Fairhall N, Sherrington C, Lord SR, Kurrle SE, Langron C, Lockwood K, et al. Effect of a multifactorial, interdisciplinary intervention on risk factors for falls and fall rate in frail older people: a randomised controlled trial. Age and ageing. 2013;43(5):616-22

21. Ferrucci L, Guralnik JM, Studenski S, Fried LP, Cutler GB, Walston JD. Designing randomized, controlled trials aimed at preventing or delaying functional decline and disability in frail, older persons: a consensus report. J Am Geriatr Soc. 2004;52(4):625-34.

22. Fried LP, Tangen CM, Walston J, Newman AB, Hirsch C, Gottdiener J, et al. Frailty in older adults evidence for a phenotype. J Gerontol Ser A Biol Med Sci. 2001;56(3):M146-57.

23. Gillespie LD, Robertson MC, Gillespie WJ, Sherrington C, Gates S, Clemson LM, Lamb SE. Interventions for preventing falls in older people living in the community. Cochrane Database Syst Rev. 2012;9(11).

24. Giné-Garriga M, Guerra M, Pagès E, Manini TM, Jiménez $R$, Unnithan VB. The effect of functional circuit training on physical frailty in frail older adults: a randomized controlled trial. J Aging Phys Act. 2010;18(4):401-24.

25. Giné-Garriga M, Roqué-Fíguls M, Coll-Planas L, Sitjà-Rabert M, Salvà A. Physical exercise interventions for improving performance-based measures of physical function in community-dwelling, frail older adults: a systematic review and meta-analysis. Archives Physic Med Rehabilit. 2014;95(4):753-769. e753.

26. Groot $C$, Hooghiemstra A, Raijmakers $P$, van Berckel $B$, Scheltens $P$, Scherder $E$, et al. The effect of physical activity on cognitive function in patients with dementia: a meta-analysis of randomized control trials. Ageing Res Rev. 2016;25:13-23. 
27. Guralnik JM, Ferrucci L. Assessing the building blocks of function: utilizing measures of functional limitation. Am J Prev Med. 2003;25(3):112-21.

28. Harada K, Park H, Lee S, Shimada H, Yoshida D, Anan Y, Suzuki T. Joint Association of Neighborhood Environment and Fear of falling on physical activity among frail older adults. J Aging Phys Act. 2016:1-28.

29. Hickman LD, Phillips JL, Newton PJ, Halcomb EJ, Al Abed N, Davidson PM. Multidisciplinary team interventions to optimise health outcomes for older people in acute care settings: a systematic review. Arch Gerontol Geriatr. 2015;61(3):322-9. https://doi.org/10.1016/j.archger.2015.06.021.

30. Higgins JP, Altman DG, Gøtzsche PC, Jüni P, Moher D, Oxman AD, et al. The Cochrane Collaboration's tool for assessing risk of bias in randomised trials. Bmj. 2011;343:d5928.

31. Hoffmann TC, Glasziou PP, Boutron I, Milne R, Perera R, Moher D, et al. Better reporting of interventions: template for intervention description and replication (TIDieR) checklist and guide. Bmj. 2014;348:g1687.

32. Howe, T. E., Rochester, L., Neil, F., Skelton, D. A., \& Ballinger, C. (2011). Exercise for improving balance in older people. The Cochrane Library.

33. Jeejeebhoy KN. Malnutrition, fatigue, frailty, vulnerability, sarcopenia and cachexia: overlap of clinical features. Current Opinion Clin Nutri Metabol Care. 2012;15(3):213-9.

34. Lang P-O, Michel J-P, Zekry D. Frailty syndrome: a transitional state in a dynamic process. Gerontology. 2009;55(5):539-49.

35. Ng TP, Feng L, Nyunt MSZ, Feng L, Niti M, Tan BY, et al. Nutritional, physical, cognitive, and combination interventions and frailty reversal among older adults: a randomized controlled trial. The American Journal of Medicine. 2015;128(11):1225-1236.e1221. Retrieved from http://www.sciencedirect. com/science/article/pii/S0002934315005677. https://doi.org/10.1016/j. amjmed.2015.06.017

36. Opdenacker J, Delecluse C, Boen F. A 2-year follow-up of a lifestyle physical activity versus a structured exercise intervention in older adults. J Am Geriatr Soc. 2011;59(9):1602-11.

37. Perera S, Mody SH, Woodman RC, Studenski SA. Meaningful change and responsiveness in common physical performance measures in older adults. J Am Geriatr Soc. 2006;54(5):743-9.

38. Pijpers E, Ferreira I, Stehouwer CD, Kruseman ACN. The frailty dilemma. Review of the predictive accuracy of major frailty scores. European I Internal Med. 2012;23(2):118-23.

39. Puts MT, Toubasi $\mathrm{S}$, Andrew MK, Ashe MC, Ploeg J, Atkinson E, et al. Interventions to prevent or reduce the level of frailty in communitydwelling older adults: a scoping review of the literature and international policies. Age Ageing. 2017;46(3):383-92.

40. Richter B, Berger M. Randomized controlled trials remain fundamental to clinical decision making in type II diabetes mellitus: a comment to the debate on randomized controlled trials. Diabetologia. 2000;43(2):254-8.

41. Rockwood K, Mitnitski A. Frailty in relation to the accumulation of deficits. J Gerontol Ser A Biol Med Sci. 2007;62(7):722-7.

42. Rubenstein LZ. Falls in older people: epidemiology, risk factors and strategies for prevention. Age Ageing. 2006;35(suppl 2):ii37-41.

43. Schutzer KA, Graves BS. Barriers and motivations to exercise in older adults. Prev Med. 2004;39(5):1056-61.

44. Silveira P, van het Reve E, Daniel F, Casati F, de Bruin ED. Motivating and assisting physical exercise in independently living older adults: a pilot study. Int J Med Inform. 2013:82(5):325-34.

45. Skjæret N, Nawaz A, Morat T, Schoene D, Helbostad J, Vereijken B. Exercise and rehabilitation delivered through exergames in older adults: an integrative review of technologies, safety and efficacy. Int J Med Inform. 2016;85(1): 1

46. Sternberg SA, Schwartz AW, Karunananthan S, Bergman H, Mark Clarfield A. The identification of frailty: a systematic literature review. J Am Geriatr Soc. 2011;59(11):2129-38.

47. Studenski S, Perera S, Wallace D, Chandler JM, Duncan PW, Rooney E, et al. Physical performance measures in the clinical setting. J Am Geriatr Soc. 2003;51(3):314-22.

48. Taraldsen K, Sletvold O, Thingstad P, Saltvedt I, Granat MH, Lydersen S, Helbostad JL. Physical behavior and function early after hip fracture surgery in patients receiving comprehensive geriatric care or orthopedic care-a randomized controlled trial. J Gerontol A Biol Sci Med Sci. 2013;69(3):338-45.

49. Thingstad, P., Taraldsen, K., Saltvedt, I., Sletvold, O., Vereijken, B., Lamb, S. E., \& Helbostad, J. L. (2016). The long-term effect of comprehensive geriatric care on gait after hip fracture: the Trondheim hip fracture trial-a randomised controlled trial. [TK-YES CJ-U FM-YES]. Osteoporos Int, 27(3),
933-942. Retrieved from http://www.embase.com/search/results?subaction= viewrecord\&from=export\&id=L606025745. https://doi.org/10.1007/s00198015-3313-9. http://surrey-primotc.hosted.exlibrisgroup.com/openurl/44SUR/ 44SUR_services_page?sid=EMBASE\&issn=14332965\&id=doi:10. 1007\%2Fs00198-015-3313-9\&atitle=The+long-term+effect+of+ comprehensive+geriatric+care+on+gait+after+hip+fracture\%3A+the+ Trondheim+Hip+Fracture+Trial\%E2\%80\%94a+randomised+controlled+ trial\&stitle=Osteoporosis+Int.\&title=Osteoporosis+International\&volume= $27 \&$ issue $=3 \&$ spage $=933 \&$ epage $=942 \&$ aulast $=$ Thingstad\&aufirst $=P$.\&auinit $=P$. \&aufull=Thingstad $+P . \&$ coden=OSINE\&isbn=\&pages $=933-942 \&$ date $=$ 2016\&auinit1=P\&auinitm=, http://download.springer.com/static/pdf/721/ art\%253A10.1007\%252Fs00198-015-3313-9.pdf?originUrl= http\%3A\%2F\%2Flink.springer.com\%2Farticle\%2F10.1007\%2Fs00198-0153313-9\&token $2=\exp =1472305623 \sim a c l=$ \%2Fstatic\%2Fpdf\%2F721\%2Fart\%25253A10.1007\%25252Fs00198-015-3313-9. pdf\%3ForiginUrl\%3Dhttp\%253A\%252F\%252Flink.springer. com\%252Farticle\%252F10.1007\%252Fs00198-015-3313-9* ${ }^{*} \mathrm{hmac}=$ fe492a13cfb309db56ee85eb1204df81a367976299fcb958af71ec8ddd2fced9.

50. Tieland M, van de Rest O, Dirks ML, van der Zwaluw N, Mensink M, van Loon $\sqcup$, de Groot LC. Protein supplementation improves physical performance in frail elderly people: a randomized, double-blind, placebocontrolled trial. J Am Med Dir Assoc. 2012;13(8):720-6.

51. Tousignant, M., Corriveau, H., Roy, P.-M., Desrosiers, J., Dubuc, N., Hébert, R., . . Beaudoin, A.J. (2012). The effect of supervised tai chi intervention compared to a physiotherapy program on fall-related clinical outcomes: a randomized clinical trial. Disabil Rehabil, 34(3), 196-201. Retrieved from https://doi.org/10.3109/09638288.2011.591891

52. Yamada M, Nishiguchi S, Fukutani N, Aoyama T, Arai H. Mail-based intervention for sarcopenia prevention increased anabolic hormone and skeletal muscle mass in community-dwelling Japanese older adults: the INE (intervention by nutrition and exercise) study. Journal of the American Medical Directors Association. 2015;16(8):654-60. Retrieved from http:// www.sciencedirect.com/science/article/pii/S1525861015001784. https://doi.org/10.1016/j.jamda.2015.02.017.

\section{Publisher's Note}

Springer Nature remains neutral with regard to jurisdictional claims in published maps and institutional affiliations.

\section{Ready to submit your research? Choose BMC and benefit from:}

- fast, convenient online submission

- thorough peer review by experienced researchers in your field

- rapid publication on acceptance

- support for research data, including large and complex data types

- gold Open Access which fosters wider collaboration and increased citations

- maximum visibility for your research: over $100 \mathrm{M}$ website views per year

At BMC, research is always in progress.

Learn more biomedcentral.com/submissions 